DATA DE

RECEPCIÓN: $20 / 06 / 2020$

DATA DE

ACEPTACIÓN:

$28 / 09 / 2020$

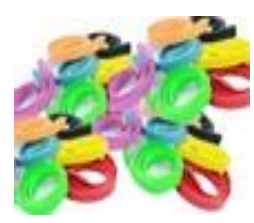

\section{LIVRO-ÁLBUM E CINEMA: UM DIÁLOGO INTERARTES}

\author{
LIBRO-ÁLBUM Y CINE: UN DIÁLOGO ENTRE ARTES
}

PICTUREBOOK AND CINEMA: AN INTERARTISTIC DIALOGUE
Ana Margarida Ramos

Universidade de Aveiro

https://orcid.org/0000-0002-6069-568X

anamargarida@ua.pt

Diana Navas

Pontificia Universidade Católica de São Paulo

https://orcid.org/0000-0002-4516-5832

diana.navas@hotmail.com

Resumo: Pretende-se, neste estudo, proceder a uma reflexão sobre as diferentes possíveis relações de proximidade e de interseção entre a narrativa fílmica e o livro-álbum, identificando vários exemplos de obras destinadas à infância e juventude que tratam o cinema como tema ou motivo, ou simples alusão pontual em termos de conteúdo, mas também de outras que se socorrem de várias técnicas cinematográficas para contarem uma história. Além disso, analisa-se, ainda, o livro $1 .^{\circ}$ Direito, de Ricardo Henriques, com ilustrações de Nicolau, que, inspirado pelo enredo do filme $A$ janela indiscreta [Rear Window, 1954], de Alfred Hitchcock, procede à sua recriação em formato de livro-álbum, revisitando, com adaptações, o imaginário fílmico.

Palavras-chave: narrativa verbo-icónica, narrativa fílmica, cinema, livro-álbum.

Resumen: El objetivo de este estudio es reflexionar sobre las diferentes relaciones de proximidad e intersección entre la narrativa cinematográfica y el libro-álbum, identificando varios ejemplos de obras dirigidas a niños y jóvenes que tratan el cine como un tema o motivo literario, o simple alusión en el contenido, pero también otras obras que usan varias técnicas cinematográficas para contar una historia. Además, también analizamos el libroálbum $1 .^{\circ}$ Direito, de Ricardo Henriques, con ilustraciones de Nicolau. Este libro, inspirado en la trama de la película de Alfred Hitchcock Rear Window (1954), procede a su recreación en formato libro-álbum, revisando, con adaptaciones, el imaginario de la película.

Palabras clave: narrativa icónico verbal, narrativa fílmica, cine, libro-álbum.

Abstract: The purpose of this text is to reflect on the different relations of proximity and intersection between the filmic narrative and the picturebook format, identifying several examples of books aimed at children and young adults that depict cinema as a theme or a literary motif, or a simple allusion in terms of content, but also others that use various cinematographic techniques to tell a story. In addition, the text also analyses the picturebook $1 .^{\circ}$ Direito, by Ricardo Henriques, with illustrations by Nicolau, since it is inspired by the plot of the film The Rear Window (1954), by Alfred Hitchcock, and it presents the movie adaption into a picturebook format, by revisiting the film imagery.

Keywords: text-iconic narrative, filmic narrative, cinema, picturebook.

Ramos, Ana Margarida e Diana Navas (2020).

"Livro álbum e cinema: um diálogo interartes". 


\section{Introdução: Literatura e Cinema e o caso do livro-álbum}

É antiga a relação entre literatura e cinema. São memoráveis os vários filmes que surgiram a partir das páginas de um livro, assim como as histórias que fizeram sucesso nas telas e ganharam, posteriormente, adaptações incríveis na sua versão impressa. A relação entre essas duas artes não se esgota, no entanto, nessa óbvia aproximação, como comprova a publicação de livros-álbum contemporâneos.

A questão da vinculação entre imagens que se sucedem, ainda que a ritmos e velocidades distintas, aproxima estas duas artes, assentes na sugestão de movimento ${ }^{1}$, assegurada pela aparência de continuidade. Se, no cinema, a sucessão de múltiplas imagens a uma velocidade constante facilita claramente essa sugestão, no contexto do livro-álbum, o leitor é chamado a reconstruir mentalmente a informação que falta entre as imagens sequenciais, que, também ao contrário do cinema, se encontram perfeitamente delimitadas e separadas entre si no espaço das páginas. Do ponto de vista cognitivo, a leitura do livro-álbum exige vários procedimentos interpretativos, que se baseiam na identificação das relações entre as imagens, identificando vários tipos diferentes (continuidade, simultaneidade, elipse...).

Ainda que se aproximem em resultado da estreita relação entre palavras e imagens na sua composição, há elementos que existem apenas num dos media: enquanto os livros-álbum se constituem como objetos táteis, em virtude da materialidade do livro, e implicam, além do envolvimento intelectual, também o envolvimento físico do leitor, que precisa de realizar o movimento de virar as páginas para que a história aconteça, os filmes geralmente incluem som e música, elementos esses não presentes nos livros-álbum. No tocante à materialidade, um outro aspecto distingue os dois media: a presença dos paratextos, que desempenham importante papel narrativo nos livros-álbum. A escolha de elementos como formato, tipo de encadernação, gramagem do papel, capa, folha de rosto, entre outros, contribuem para que a narrativa se inicie antes mesmo de o leitor ler a primeira página, aspetos esses não facilmente recuperáveis através dos créditos, na narrativa cinematográfica.

Mesmo que, aparentemente, o movimento da câmara no cinema possa ser comparado à escolha do foco narrativo na literatura - a câmara objetiva corresponderia à narrativa em terceira pessoa, e a câmara subjetiva consistiria no assumir do ponto de vista de uma das personagens e dos seus movimentos - percebemos que esta aproximação não é tão simples quando pensamos no

\footnotetext{
${ }^{1}$ O chamado fenómeno phi, definido por Max Wertheimer em 1912 e aplicado a uma teoria do cinema por Hugo Münsterbergin em 1916, permite a perceção de movimento após a visualização de duas imagens paradas observadas sequencialmente.
} 
representar do que se passa no interior de uma personagem num filme, por exemplo. É graças à possibilidade de jogo com diferentes planos, ângulos e cortes, promovidos pela movimentação da câmara, que diferentes efeitos de sentido são gerados, os quais, no livro-álbum, são recuperados através de diferentes estratégias de ilustração.

O que pretendemos demonstrar é que ainda que algumas das estratégias narrativas no livroálbum também possam ser encontradas no cinema e vice-versa, a sua aplicação e especificidade são significativamente distintas. Por esse motivo, de acordo com Kuhn e Schmidt (2013), parece apropriado falar de "analogias" entre a narrativa do livro-álbum e a cinematográfica. Essas analogias são muito mais complexas do que é sugerido por qualquer mera "tradução" ou "adaptação" de um meio para outro.

Bettina Kümmerling-Meibauer, num texto sobre as tendências contemporâneas do livroálbum europeu, chamava a atenção para a influência que outros media exercem sobre o livro-álbum, com a apropriação de técnicas e de procedimentos de vários tipos:

\begin{abstract}
An attentive observer will also notice that comics, manga, films, and computer games apparently have a considerable effect on the creation of picturebooks, as is evident in the integration of typical patterns derived from these media, such as speed lines, speech bubbles, camera perspectives, and multiple story levels (Kümmerling-Meibauer, 2015: 249).
\end{abstract}

Assim, ainda que reconheçamos o relevo crescente das adaptações ${ }^{2}$ de livros-álbum ao cinema, nomeadamente o de animação, mas também a outros media, como as aplicações digitais ou os jogos de computador e de vídeo, não é nosso objetivo proceder a um estudo dos procedimentos por que passam as narrativas verbo-icónicas nesse processo, mas identificar aquilo que elas já integram de outros media, numa lógica cada vez mais comum de hibridismo de géneros, formatos e discursos. Os estudos sobre intermedialidade têm-se revelado mais produtivos quando aplicados ao universo da literatura infantil, tendo em conta a sua natureza intrinsecamente multimodal, ocupando-se quer das questões da relação da literatura com outras artes, quer ainda das adaptações a outros media (Mackey, 2002). No caso do livro-álbum, o número crescente de novos produtos criados a partir dele exigem uma aproximação cada vez mais global a este formato, estudado a partir de múltiplos pontos de vista. O próprio estatuto do criador de livro-álbum também se tem vindo a alterar em alguns casos, com as colaborações frequentes dos autores nos processos de adaptação a outros media, como o trabalho de Shaun Tan, Jannie Baker ou Brian Selznick, por exemplo, ilustram. Mas o cariz assumidamente experimental e desafiador dos livros-álbum contemporâneos, em particular os credores dos seus desenvolvimentos pós-modernos, obrigam a leituras que têm necessariamente de ter em conta as relações com outras

\footnotetext{
${ }^{2}$ Sobre as relações entre livros infantis e outros media, ver Rosen (1996).
} 
artes e media.

Deste modo, procura-se, neste texto, proceder a uma reflexão sobre as diferentes relações de proximidade e de interseção entre a narrativa fílmica e o livro-álbum para crianças, identificando exemplos variados, com diferentes origens, de obras que tratam o cinema como tema ou motivo da história, mas também de outras que se socorrem de várias técnicas cinematográficas para construírem a narrativa. Além disso, analisa-se, ainda, de forma mais detalhada, o livro-álbum português $1 .^{\circ}$ Direito (Pato Lógico, 2020), de Ricardo Henriques, com ilustrações de Nicolau, que, inspirado pelo enredo do filme $A$ janela indiscreta [Rear Window, 1954], de Alfred Hitchcock, procede à sua recriação em formato de livro-álbum, revisitando, com adaptações, o imaginário fílmico.

\section{A presença do cinema e do discurso fílmico no livro-álbum}

A proximidade entre o livro-álbum e outras formas de comunicação artística é estabelecida com base na sua natureza multimodal, ainda que, na esteira da reflexão de Maria Nikolajeva, o formato mantenha especificidades intrínsecas:

\footnotetext{
The unique character of picturebooks as an art form derives from their combination of two levels of communication, the verbal and the visual. In this, picturebooks are a synthetic medium, like theatre or film, where the overall meaning is assembled by the receiver in the interaction between the different communicative means. Unlike theatre or film, picturebooks are discontinuous and have no fixed duration. Unlike theater, but similar to film, picturebooks are twodimensional. Unlike both theatre and film, picturebooks do not presuppose oral communication, although they certainly can be - and often are - read aloud. The actual reader is not the sender in the communicative process, however, but simultaneously a performer, like an actor in theatre or film, and a receiver or coreceiver, a co-reader. (Nikolajeva, 2002: 85)
}

Uri Shulevitz, por seu turno, sublinha o parentesco ou a afinidade notória entre estas artes, com relevo para o cinema mudo, quando refere que "the kinship between picture books and theatre or film, the silent film in particular, becomes evident" (Shulevitz, 1996: 240).

Os estudos sobre a narratividade em diferentes media (Ryan, s/d) são cada vez mais abrangentes e integram uma assinalável diversidade de fenómenos, desde os meios de comunicação de massas, como a televisão, a rádio e, mais recentemente, a internet, a formas artísticas mais tradicionais, como a literatura, a pintura ou a música.

O conceito de "remediação" , que foi usado para explicar as relações entre diferentes media, numa relação de constante procura de "remediar" as limitações que eles apresentam, tem vindo a

\footnotetext{
${ }^{3}$ Os estudos de cariz intermedial chamam a atenção para a relação constante que os media estabelecem entre si, numa lógica que, muitas vezes, aponta para a sua substituição ou superação. Sobre esta questão mais abrangente, ver Bolter \& Grusin (2000).
} 
ser substituído pelo de "intermedialidade", que, de acordo com Wolf (2008), pode ser interpretado em sentido amplo ou restrito. No primeiro caso, pode ser entendido como uma forma equivalente da intertextualidade, primeiro aplicado ao contexto das artes (relações interartes) e, posteriormente, dos media, no segundo, refere-se à inclusão de mais do que um medium num determinado objeto ou produção. Este autor (Wolf, 2005) define, ainda, uma plêiade de conceitos para caracterizar diferentes relações entre os media: "plurimedialidade" aplica-se a objetos artísticos que incluem vários sistemas semióticos; "transmedialidade" caracteriza fenómenos narrativos que não estão ligados a um medium específico; “adaptações intermediais" para adaptações de um medium para outro; "referência intermedial" quando um texto trata outro medium como tema, alude a ele, o cita ou imita.

No caso deste estudo, será sobretudo no âmbito da "referência intermedial" que nos situaremos, na medida em que se pretende perceber como o livro-álbum, também ele um formato "multimodal", que resulta da combinação sinérgica de várias linguagens, se refere a um outro medium, neste caso a narrativa fílmica (Grodal, 2005), o tematiza, cita ou imita, mas também se apropria das suas técnicas.

Em consonância com os estudos desenvolvidos por Perry Nodelman (1986), Amy Spaulding (1995), Jens Thiele (2000) e Sandra Beckett (2012), Tobias Kurwinkel (2018), partindo de uma perspetiva intermedial ${ }^{5}$, propõe a denominação de "filmic writing" para definir a incorporação de técnicas cinematográficas na composição de obras literárias. De acordo com o pesquisador:

[...] filmic writing does not only encompass transformation of cinematic techniques in literature, such as montage or zoom, filmic writing also include allusions to the medium of film as such, to its cultural, institutional, and productional background, to its language and style (which imitate the dreamlike nature and stream of consciousness movement of screen images), or it simply refers to a narrative's ready-madeness for adaptation (Kurwinkel, 2018: 326).

Segundo esta perspetiva, autor e ilustrador compõem como se fossem diretores de cinema, como se dispusessem dos instrumentos cinematográficos para a elaboração de um livro. Considerando, no entanto, que distintos e específicos são os meios utilizados em cada um dos media, o que se cria, na realidade, é uma "ilusão cinematográfica" no livro-álbum que evoca ou imita técnicas cinematográficas - seja por meio do texto, da ilustração, ou de ambos - valendo-se dos seus próprios meios de expressão e, consequentemente, também das suas limitações.

\footnotetext{
${ }^{4}$ Para tal, será igualmente relevante ter em conta o conceito de "multimodalidade", cada vez mais usado no contexto do livro-álbum, pelo facto de este formato incluir texto e imagem.

${ }^{5}$ Valemo-nos, aqui, do conceito de media proposto por Wolf: "conventionally distinct means of communicating cultural contents. Media in this sense are specified principally by the nature of their underlying semiotic system (involving verbal language, pictorial signs, music, etc., or, in case of composite media such as film, a combination of several semiotic system), and only in the second place by technical or institutional channels" (Wolf, 2005: 253).
} 
De entre as técnicas do cinema incorporadas pelo livro-álbum, Kurwinkel esquematiza (2018: 328) algumas das principais, com destaque para as questões de imagem, som e edição, cada uma com várias subdivisões. No caso da imagem, por exemplo, é distinguido o trabalho de câmara da mise-en-scène. No primeiro analisa-se quer o tipo de "tomada de imagem”, quer o movimento e o ângulo usados. Já a mise-en-scène que, no cinema, consiste na disposição de objetos para serem filmados, tem implicações ao nível da iluminação, da cor, das proporções e da composição. O som, elemento presente nas narrativas cinematográficas, pode ser encontrado no discurso, nos efeitos sonoros e na música de fundo, através de referências textuais e visuais feitas a estes elementos. A edição, que inclui o corte e a montagem, técnicas inerentes à linguagem cinematográfica, podem, por seu turno, ser incorporadas nas transições entre as cenas e nos jogos de página dupla do livro.

Tobias Kurwinkel sublinha, no seu estudo, que o recurso pontual a elementos cinematográficos como os mencionados acima não configura por si só um exemplo de escrita fílmica, mas a sua combinação e apresentação sustentada ao longo do livro-álbum pode confirmar um exemplo de intermedialidade com o cinema ou de discurso fílmico no livro-álbum. O caráter cinematográfico de alguns livros-álbum, ilustrado pelo investigador através de exemplos concretos, pode decorrer, assim, quer do uso de técnicas cinematográficas específicas, manipulando elementos como os que referimos anteriormente, quer como princípio narrativo, isto é, como elemento estrutural do ponto de vista da construção do livro-álbum, "by rendering possible visual journeys through time and space (...), by representing temporal structures in a filmic manner (..), or by using the structure and dramaturgy of film as a narrative technique” (Kurwinkel, 2018: 335), o que nos parece claramente ainda mais relevante e original.

\section{O cinema como tema, motivo ou alusão}

O cinema e o imaginário que o envolve, desde a produção dos filmes, aos atores e atrizes que os protagonizam, incluindo o próprio ato de fruição desse espetáculo e os rituais que o caracterizam, têm exercido um certo fascínio sobre os criadores de livros para a infância que, de forma mais consistente ou mais marginal, o tomam como tema e ou motivo literário.

Desde as publicações de cariz biográfico, destinadas a diferentes tipos de leitores (como Audrey: My First Audrey Hepburn (Frances Lincoln, 2018), texto de Isabel Sanchez Vegara, ilustrações de Amaia Arrazola), a livros que tematizam a ida ao cinema, explorando a magia da sétima arte (como Maisy goes to the movies (Candlewick Press, 2014), de Lucy Cousins), a variedade de propostas é muito significativa, abrangendo um amplo grupo de leitores. 
Anthony Browne, por exemplo, em $A$ minha mãe (Caminho, 2008) recorre a alguns ícones do cinema para reforçar sugestões de beleza, como acontece com uma alusão visual a Marilyn Monroe, ou de heroicidade, como o Super-homem (que surge noutras obras do autor, como em Gorilla $\left.{ }^{6}\right)$. Na série de livros dedicada a Willy, personagem de eleição de Browne, o seu interesse pelas artes, com relevo para a pintura, fica claramente patente, estendendo-se também à música, ao cinema e a algumas das suas mais emblemáticas figuras. Em Willy the Dreamer (Walker, 1997), a dada altura da narrativa, a personagem sonha que é uma estrela de cinema e a ilustração junta personagens de diferentes adaptações literárias à sétima arte, como é o caso de Mary Poppins, Drácula, Tarzan e Frankenstein, entre outros filmes e personagens memoráveis, como Charles Chaplin (fig. 1). Aliás, a atração do criador pelo imaginário cinematográfico deu origem ao volume King Kong (Picture Corgi, 2005), numa adaptação visual do clássico filme de 1933.
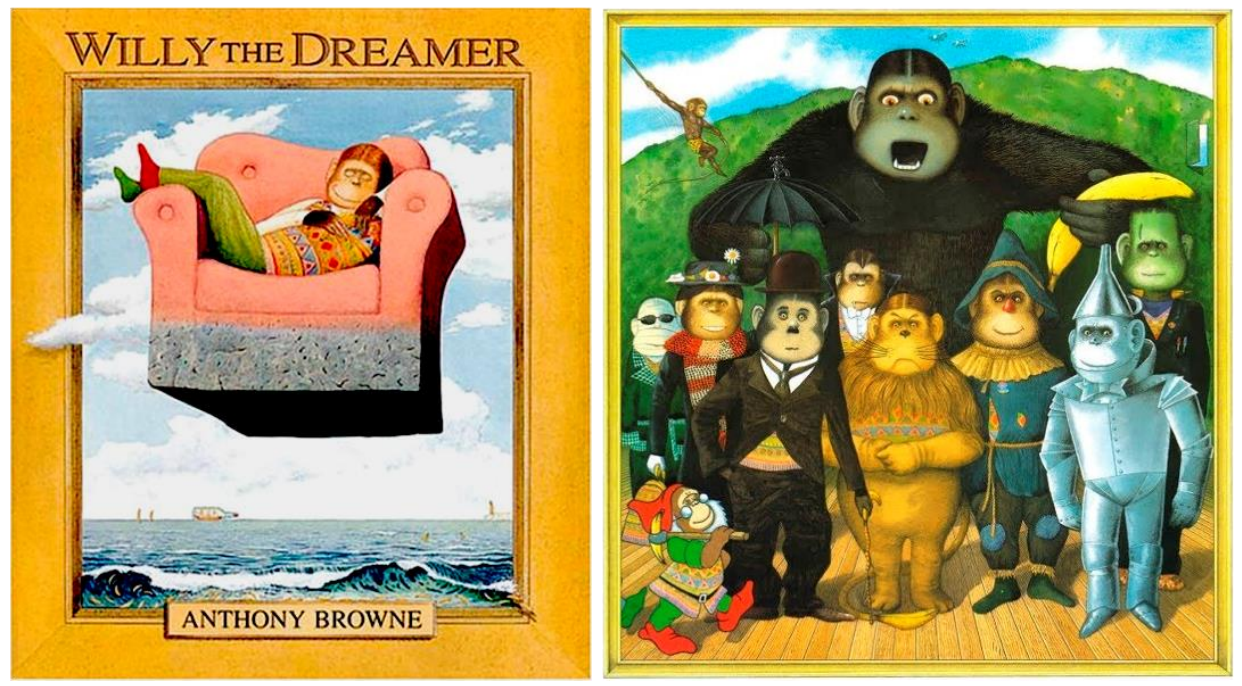

Figura 1: Capa e ilustração de Willy the Dreamer, de Anthony Browne.

Também a criadora portuguesa Catarina Sobral presta, nas suas obras, tributo a alguns mestres do cinema, como acontece no volume $O$ meu avô (Orfeu Negro, 2014), cuja capa e contracapa aludem, respetivamente, aos filmes Mon Oncle (1958), de Georges Tati e Modern Times (1936), de Charles Chaplin. Além do mais, a própria técnica de ilustração usada e o ambiente recriado neste premiado livro-álbum da autora são inspirados pela poética do filme de Tati, incluindo alguns elementos pontuais da narrativa.

Yara Kono, por seu turno, de forma mais pontual (fig. 2), alude ao clássico de Georges Méliès A Viagem à Lua (1902), com a inclusão de uma das mais icónicas imagens do filme no álbum Imagem (Planeta Tangerina, 2016), onde procede à recriação visual do poema-canção de Arnaldo

\footnotetext{
${ }^{6}$ Neste volume, Gorilla (Julia McRay Books, 1983), as personagens vão ao cinema e é através da ilustração que o leitor identifica o filme do Super-Homem que foram ver.
} 
Antunes. Recorde-se, aliás, como a figura e a obra de Méliès foram centrais na criação do romance híbrido de Brian Selznick The invention of Hugo Cabret (Scholastic Press, 2007), posteriormente também ele convertido em filme (2011) com extraordinário sucesso.

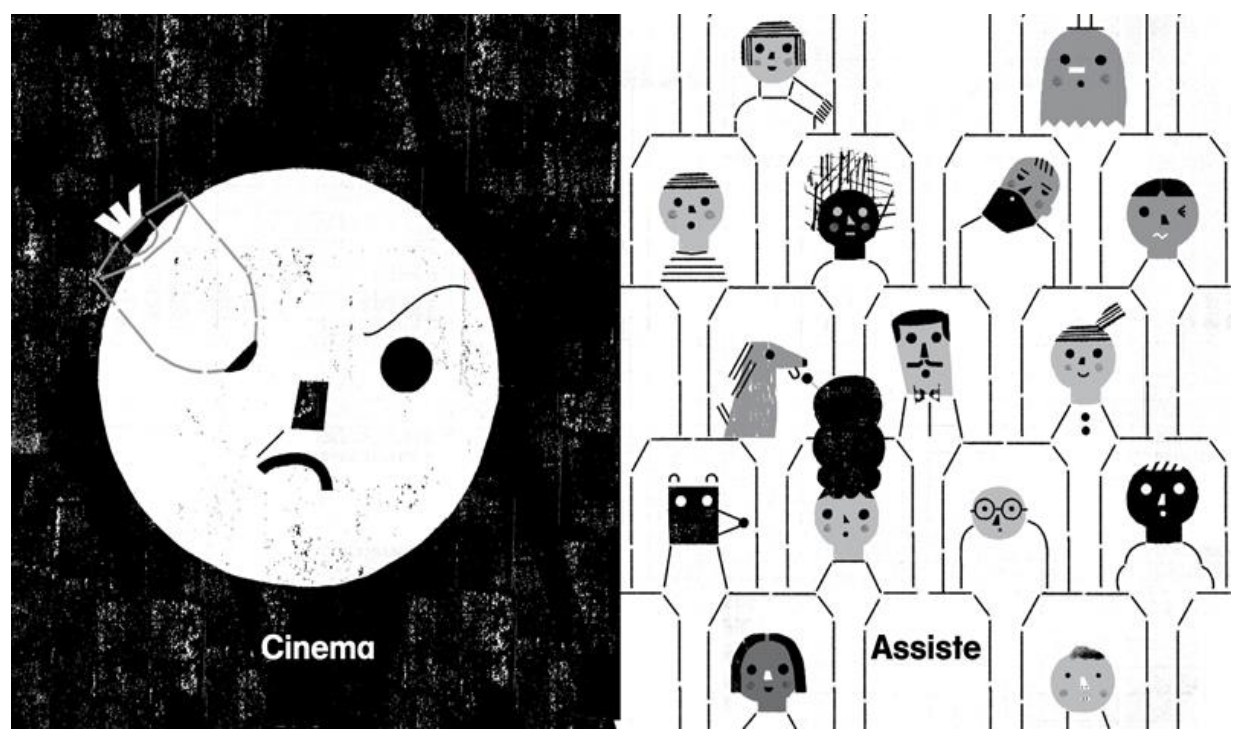

Figura 2: Dupla página do livro Imagem

Ondjaki, em Uma escuridão bonita (Caminho, 2013), refere-se a um tipo de cinema alternativo, o Cinema Bu, cuja existência efémera (mas também profundamente mágica), constitui a sua essência. Trata-se, na realidade, de um substituto pobre do cinema, experienciado pelas crianças nos bairros pobres de Luanda, aproveitando as faltas constantes de luz e as sombras projetadas pelos carros em movimento nas ruas. Caracterizado como "veloz e pobre" (Ondjaki, 2013: 84), mas intenso, porque é “vivido num tempo mais curto que a chama de um fósforo" (idem), esta forma de divertimento esclarece acerca da criatividade das crianças, habituadas a tirarem partido das situações mais banais, mas também a pobreza e a privação de formas de diversão, limitadas a verem a noite iluminada e projetada pelos faróis dos carros que passam na estrada. As ilustrações, de António Jorge Gonçalves, tiram partido das sugestões de movimento, através da inclusão de uma dupla página dobrada, que, uma vez desdobrada, duplica o espaço disponível para as ilustrações, simulando a projeção do cinema Bu e explorando os efeitos de luz e sombra e de movimento que lhe estão associados.

Mais recentemente, Ana Pessoa e Bernardo Carvalho colaboraram na produção de uma novela gráfica para adolescentes, intitulada Desvio (Planeta Tangerina, 2020), onde, para além de constituir uma linha temática do volume ${ }^{7}$ o cinema (a par das narrativas de jogos digitais) é também

\footnotetext{
${ }^{7}$ Miguel, o protagonista, está a viver uma crise existencial e não sabe que opções tomar em relação ao seu futuro. Ao descobrir o gosto pelo cinema, onde vai duas vezes durante a narrativa, acaba por decidir estudar nesta área, começando a preparar a criação de um filme. O romance vai dando conta do processo criativo, através das constantes tomadas de
} 
relevante para o processo da narrativa visual, tendo em conta o significado de elementos como os planos, as perspetivas e as próprias sequências de imagens, claramente apostadas na sugestão de movimento e ação, mas também estagnação, além de emoções e estados de espírito, analepses ou mesmo narrativas encaixadas na principal. A alternância de níveis narrativos (o principal e o do filme a que as personagens assistem) é construída numa sequência que assenta no conhecimento prévio que o leitor tem do universo convocado (fig. 3), neste caso, uma alusão a algumas das cenas mais emblemáticas do filme Pulp Fiction (1994), de Quentin Tarantino.
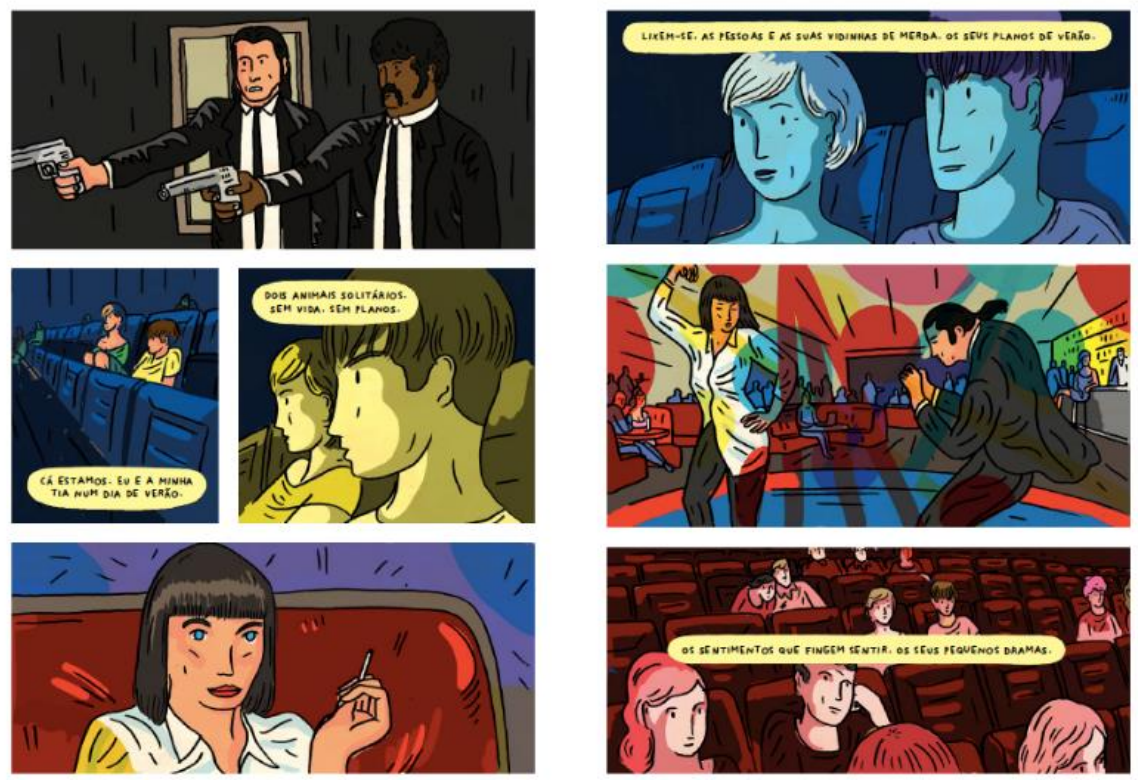

Figura 3: Dupla página de Desvio.

Cine Bijou (Cosac Naify, 2012), escrito por Marcelo Coelho e com ilustrações de Caco Gualhardo, traz a referência ao cinema já no seu título. Nele, através de um relato memorialístico, o autor apresenta as suas experiências num pequeno e simbólico cinema da cidade de São Paulo, especializado na exibição de filmes de vanguarda. Recorrendo a uma linguagem contemporânea e dinâmica - no texto e nas ilustrações - a obra alterna factos e ficção, possibilitando ao jovem leitor conhecer um pouco do espaço urbano de uma importante cidade brasileira.

Também fazendo referência ao cinema a partir do seu título, Monstros do cinema (Sesi, 2016), de Augusto Massi e ilustrações de Daniel Kondo, apresenta-se como um livro em tiras que, a partir da manipulação das suas partes pelo leitor, possibilita a montagem e (re)construção de diferentes monstros das narrativas cinematográficas, permitindo que o terror seja transformado, em resultado das composições possíveis, em humor (fig.4).

imagem que o protagonista realiza com o seu telemóvel, uma espécie de filtro através do qual o leitor tem acesso ao real. 


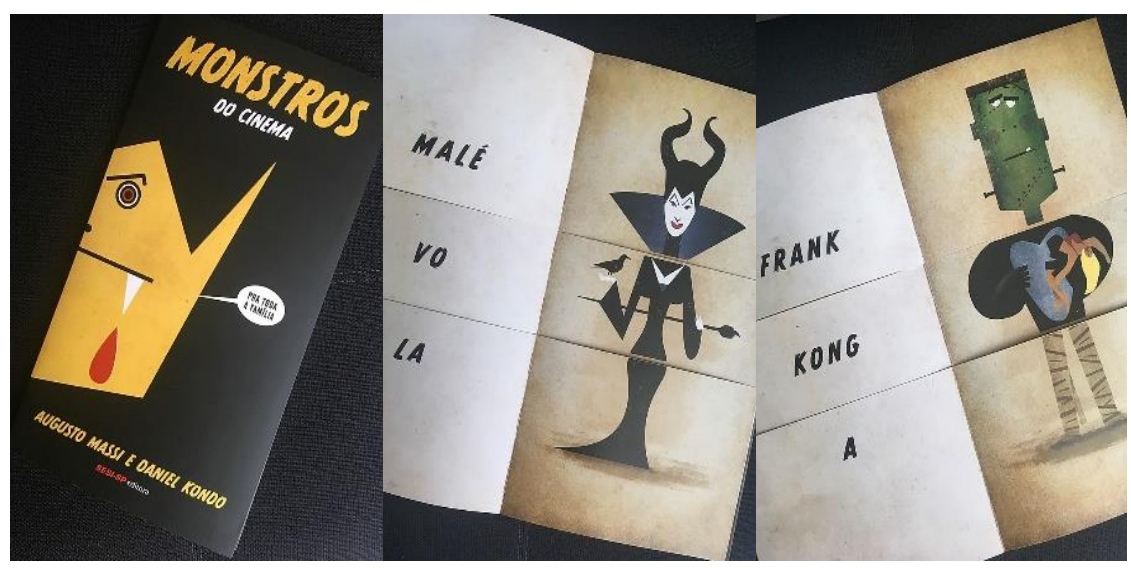

Figura 4: Capa e diferentes combinações das tiras em Monstros do cinema.

A obra traz também o levantamento histórico de onze monstros do cinema, destacando os filmes onde apareceram pela primeira vez e oferecendo um panorama evolutivo das suas representações.

\section{O recurso a estratégias cinematográficas na narrativa visual do livro-álbum}

Para além de alguns exemplos clássicos de livros-álbum que apresentam, na sua construção, um discurso ou estrutura fílmica, como é o caso dos volumes Zoom (Viking, 1995) e Re-Zoom (Viking, 1995), de Istvan Banyai, ou Flotsam (Clarion, 2006), de David Weisner, já alvo de estudo (Kurwinkel, 2018), interessa aqui identificar outras obras em língua portuguesa, de Portugal ou do Brasil, ou mesmo em outras línguas, suscetíveis de serem lidas nesta perspetiva, alargando as possibilidades de análise do livro-álbum e confirmando a sofisticação e complexidade de um formato que não se esgota numa única leitura possível.

No contexto português, merece referência o trabalho de ilustração de Bernardo Carvalho, sobretudo quando o criador tira partido da técnica mais realista, explorando as possibilidades narrativas das variações de planos, perspetivas e pontos de vista, com nítido efeito cinematográfico. A agilidade do traço combinada com a preocupação com o pormenor na composição das cenas, incluindo nelas muitos elementos interessantes, sem esquecer a variedade de planos e ângulos, criam sugestivos efeitos visuais. Por exemplo, em $O$ mundo num segundo (Planeta Tangerina, 2008), cada uma das 23 duplas páginas que forma o livro cristaliza o mesmo segundo, da mesma hora, do mesmo dia em 23 locais diferentes do mundo inteiro. Entendido como uma sequência de 23 frames simultâneos, o livro constituiria, através do processo de edição e montagem, a possibilidade de o leitor ver o filme da sequência desses segundos simultâneos. O que é curioso é que para além dessas imagens serem obviamente diferentes, na medida em que percorrem espaços geográficos muito distintos do planeta, houve uma preocupação em introduzir também grande variedade no tipo de 
tomada de imagem, alterando os planos, os ângulos e os enquadramentos. Desta forma, a rigidez de cada uma das ilustrações, ao fixar o tempo numa imagem, é equilibrada pela diversidade sucessiva de movimentos de câmara, introduzindo ação e dinamismo através da montagem (fig. 5). Assim, podemos encontrar, no que toca aos enquadramentos, planos gerais e consideravelmente abertos, bem como planos muito apertados, incidindo sobre um detalhe de uma imagem, entre outros; mas também variações em termos do ângulo vertical, através do recurso ao zenital e ao plongé, por exemplo; e do ângulo horizontal, com planos frontais, laterais e traseiros. As combinações destes elementos permitem uma variedade considerável de propostas que assegura a surpresa no movimento do virar de página, imprimindo ritmo e dinamismo à leitura.

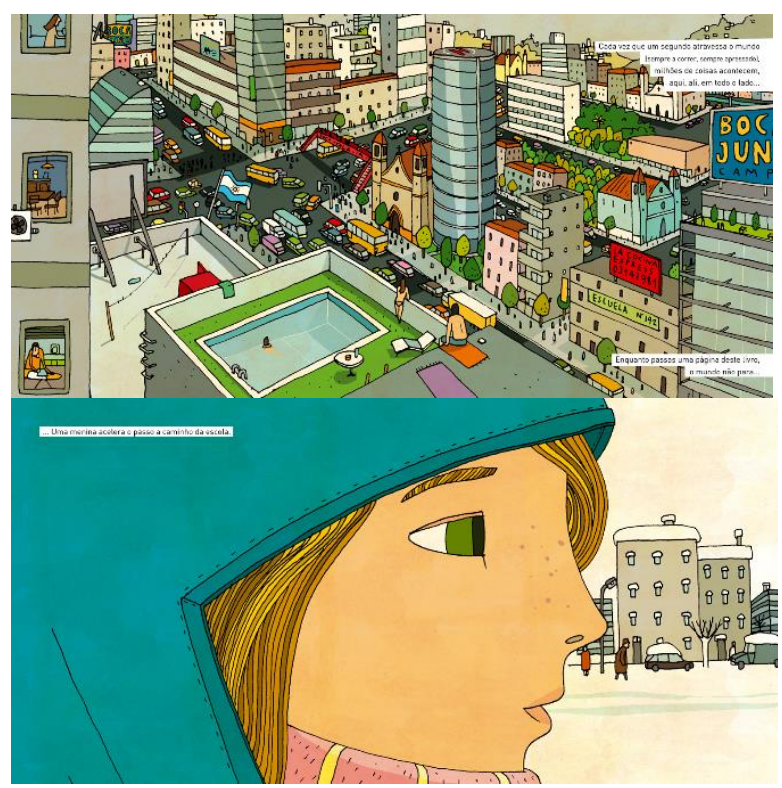

Figura 5: Exemplo de duas duplas páginas de $O$ mundo num segundo.

A sugestão cinematográfica também pode ser vista em Daqui ninguém passa! (Planeta Tangerina, 2014), desta vez com uma estratégia oposta, dado que a câmara agora apresenta uma posição fixa e cada virar de página sugere o movimento das personagens ocorrido entre elas, através da sua disposição em espaços diferentes da página, numa sucessão cronológica sequencial (fig. 6).
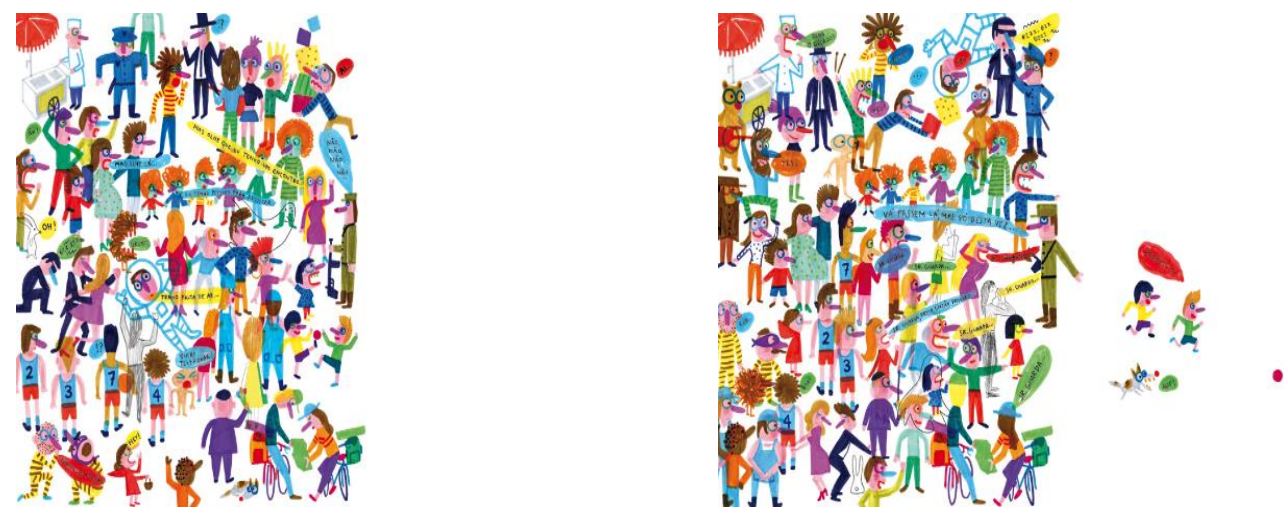

Figura 6: Exemplo de duas duplas páginas de Daqui ninguém passa. 
Monstros, de Alice Hoogstad, originalmente editado pela Lemniscaate em 2015, e publicado no Brasil, em 2018, pela editora Amelí, é também um exemplo de obra que alude à linguagem cinematográfica. Neste livro-imagem, uma menina, com uma caixa de lápis de cor, percorre uma cidade toda a preto e branco. Se, no início, ela desenha um coração num muro, à medida que se desloca, passa a desenhar monstros, os quais vão ganhando vida. A cidade é sinuosa, repleta de detalhes, habilmente capturados pela ilustração, e nela ocorrem várias narrativas paralelas. Graças aos diferentes planos empregados pela ilustradora, somos apresentados à mesma cidade - presente logo na página dupla que inicia a narrativa - a partir de diferentes perspetivas a cada virar de página. Ou seja, se inicialmente somos expostos à cidade na sua visão panorâmica, a cada virar de página que corresponde ao deslocamento da menina -, por meio da incorporação da técnica de aproximação da câmara em tomadas moventes (fig. 7) em panorâmica, conhecemos cada parte desta cidade e as narrativas paralelas que ali se desenvolvem.

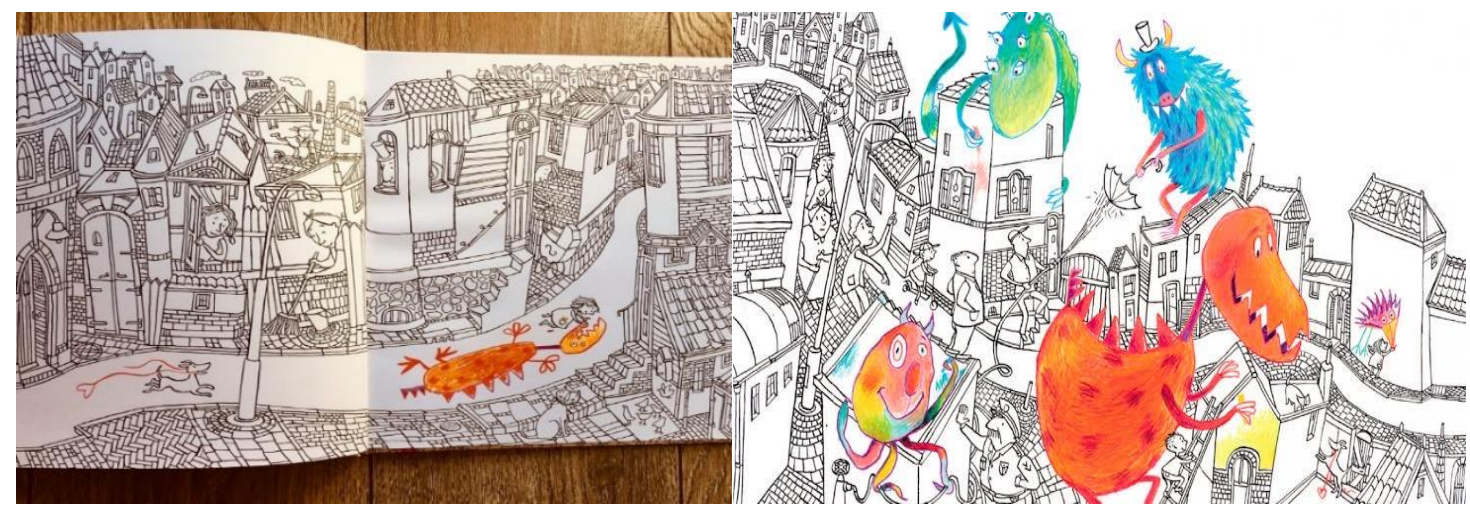

Figura 7: Jogo de página dupla com tomadas moventes em panorâmica em Monstros.

É interessante observar como o uso das cores - atribuídas às figuras dos monstros - contribui também para a ideia de movimento que se imprime na narrativa, uma vez que se destacam no meio das ilustrações a preto e branco, surgindo em diferentes posições no jogo da página dupla.

O Presente, primeiro livro-álbum sem texto de Odilon Moraes, publicado em 2010 pela editora Cosac Naify, ainda que, tematicamente, não faça qualquer menção ao cinema, vale-se claramente das suas técnicas compositivas no seu processo de ilustração. A obra apresenta-nos um cenário muito comum em solo brasileiro: o clima de euforia em jogos da Copa do Mundo. Nela, um menino presenteado com uma camisa da seleção brasileira, em dia de jogo do Brasil, assiste, juntamente com um grupo de familiares e amigos, à derrota do país. Triste, vai, com outros meninos, jogar à bola. Diferentemente da seleção brasileira, no entanto, ele sai vitorioso deste jogo, conduzindo o leitor a questionar a qual presente, efetivamente, se refere o título do livro.

Já na sua capa, contracapa e abas, somos expostos a uma tomada sem cortes, uma visão panorâmica da vila onde se desenrola a história. Ao longo da narrativa, o ilustrador, como que dotado 
de uma câmara, recorre ao uso de perspetivas, enquadramentos, zoom e o grande plano, imprimindo ao volume uma sensação de movimento - reforçado pelo uso da cor amarela da camisola - e da sugestão da passagem do tempo.
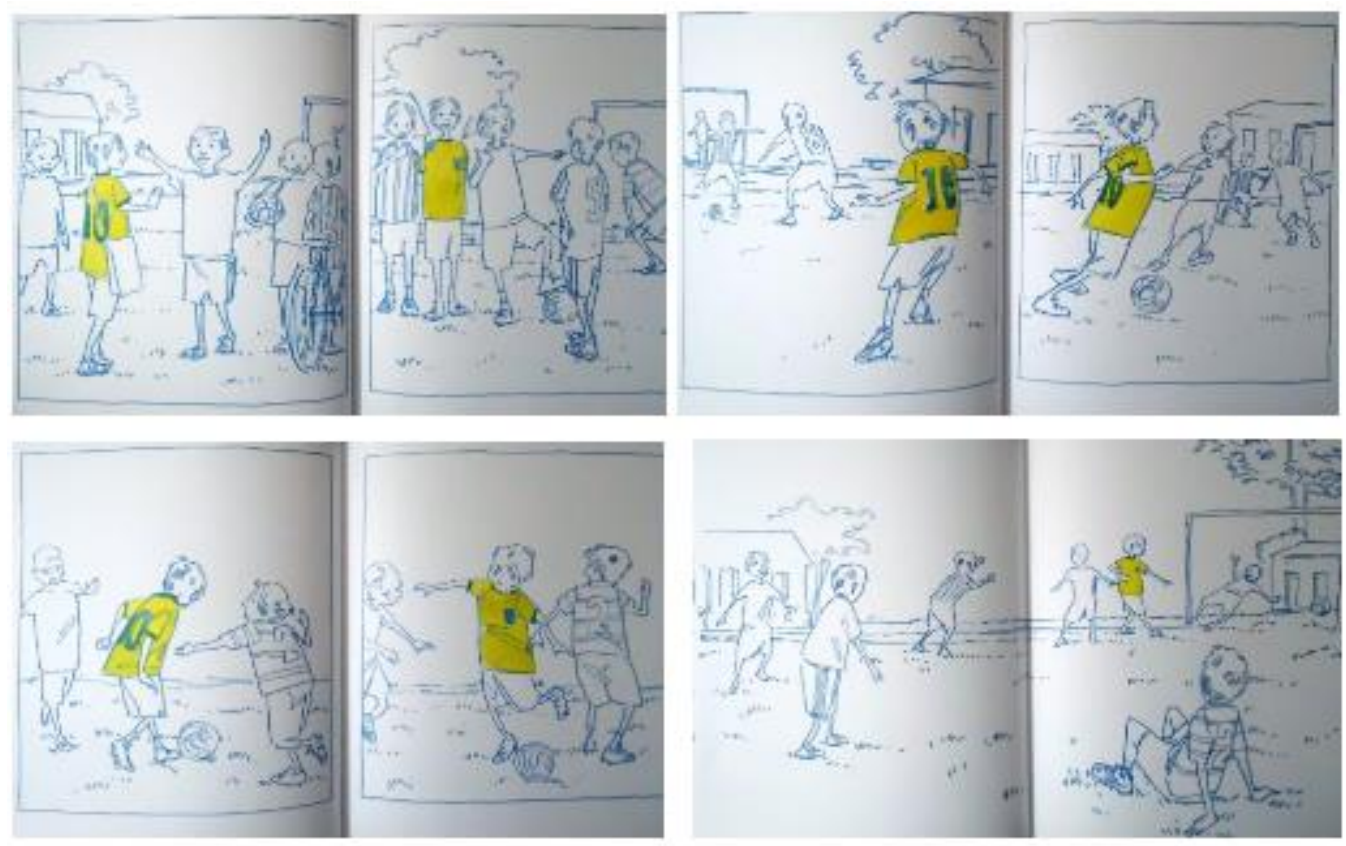

Figura 8: Cumprimento entre os amigos, escolha da equipa, passe, drible 1, drible 2, drible 3, chuto e golo em $O$ Presente.

Assim como ocorre na narrativa cinematográfica, as ações registadas por cada imagem inscritas em cada quadro encadeiam uma harmonia, resultando disso a impressão de fluidez, tanto no movimento como na temporalidade. O movimento de virar as páginas - se empreendido rapidamente - parece simular a própria experiência do conjunto de fotogramas que constituem as cenas do filme (fig. 8).

É também com a sintaxe do cinema que nos deparamos em The Whale (2016, Templar), de Ethan e Vita Murrow. Partindo de uma lenda que diz haver uma grande baleia-pintada no oceano o seu avistamento há cinquenta anos nunca foi confirmado - , dois jovens observadores de baleias partem em sua busca, um munido de equipamento de gravação de som e outro com uma câmara. Quando os seus barcos colidem, eles juntam os seus recursos para capturar provas de que a mítica baleia existe. A eventual observação é um momento mágico, especialmente quando as crianças descobrem que foram os seus próprios avós que vislumbraram a baleia cinquenta anos antes. A aventura é narrada com impressionantes desenhos em grafite que, além de capturarem o drama e a beleza do oceano e da imponente baleia, incorporam, à semelhança de uma câmara, o jogo de zoom in e zoom out, imprimindo a sensação de ação e movimento à narrativa. 


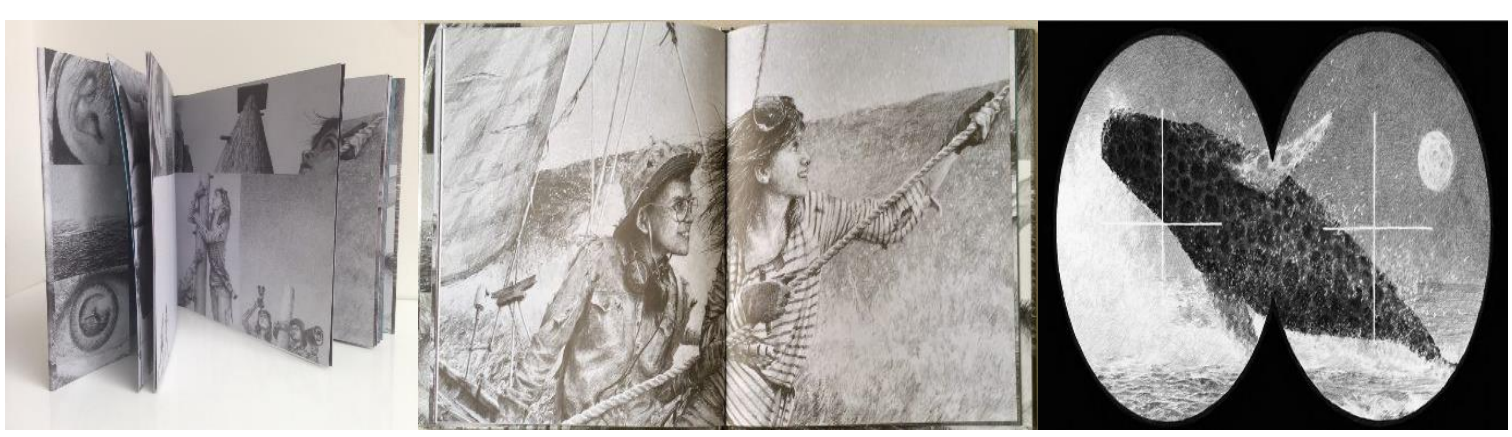

Figura 9: Diferentes formatos de quadros e jogo com planos e ângulos.

Graças aos diferentes formatos de quadros que compõem as páginas do livro - dispostos ora horizontal, ora verticalmente, ora explorando todo o espaço da página dupla -, bem como aos diferentes planos e ângulos adotados, os quais são habilmente articulados, tornamo-nos capazes de nos aproximarmos dos jovens protagonistas e de, com eles, nos aventurarmos, sentindo o impacto das ondas, a colisão dos barcos, assim como a emoção e a expectativa que carregam. É válido notar que chegamos, inclusive, a olhar através dos seus binóculos, conforme se verifica na figura 9. Contribuem, ainda, para o alcance deste efeito as linhas, o sombreamento e uso da luz, à semelhança do que ocorre nas narrativas cinematográficas, assim como as ilustrações realistas inspiradas em fotografias, observáveis desde a sua capa.

O diálogo entre literatura e cinema, seja em termos temáticos, seja por meio da incorporação de técnicas cinematográficas, é notável, de maneira exemplar, na conhecida obra de Brian Selznick A invenção de Hugo Cabret, publicada, no Brasil, em 2011, pela editora SM. Se muitas são as referências a filmes, bem como à história do cinema - visto que o enredo recupera a trajetória de Georges Méliès, figura inauguradora da ficção científica na sétima arte - variadas são também as técnicas cinematográficas integradas na arquitetura da obra. Selznick configura o seu livro como se fosse um filme a preto e branco antigo, o que é conseguido, principalmente, em função das ilustrações empregadas. O autor, nas páginas iniciais, já simula a experiência do cinema, inserindo páginas de cor preta, que representam a escuridão das salas de projeção de filmes. A esse respeito, o leitor é advertido num breve texto introdutório: "Mas antes de virar a página, quero que você se imagine sentado no escuro, como no início de um filme. Na tela, o sol logo vai nascer, e você será levado em zoom até uma estação de trem no meio da cidade [...]” (Selznick, 2007: IX).

Além disso, Selznick recupera a técnica de composição dos filmes antigos, construídos, literalmente, a partir de muitas fotos tiradas em sucessão e projetadas na tela como um flip book para construir movimento. $\mathrm{O}$ autor emprega exatamente essa técnica ao contar a história, incluindo várias imagens em sucessão, o que permite que ela seja narrada através das imagens em vários momentos. É interessante também notar que, nas páginas em que nos deparamos com o texto 
verbal, este surge no meio da página em branco, a qual, no entanto, apresenta molduras pretas, como se da tela de um cinema mudo se tratasse.

Mantendo uma clara associação com o cinema nas suas origens, as ilustrações do livro são todas a preto e branco, com a técnica lápis em papel Fabriano Artístico, exceto a capa e a contracapa. Entre as ilustrações, surgem reproduções originais de cenas de filmes variados, como Viagem à lua (1902); A Clock Store (1931), desenho animado de Walt Disney; Le Million (1931), de René Clair, entre outros, possibilitando ao jovem leitor o contacto mais direto com as produções fílmicas citadas (fig.10). As sequências de ilustrações, por seu turno, também guardam semelhança com o cinema: há sempre uma continuidade que permite ao leitor acompanhar a narrativa através delas.

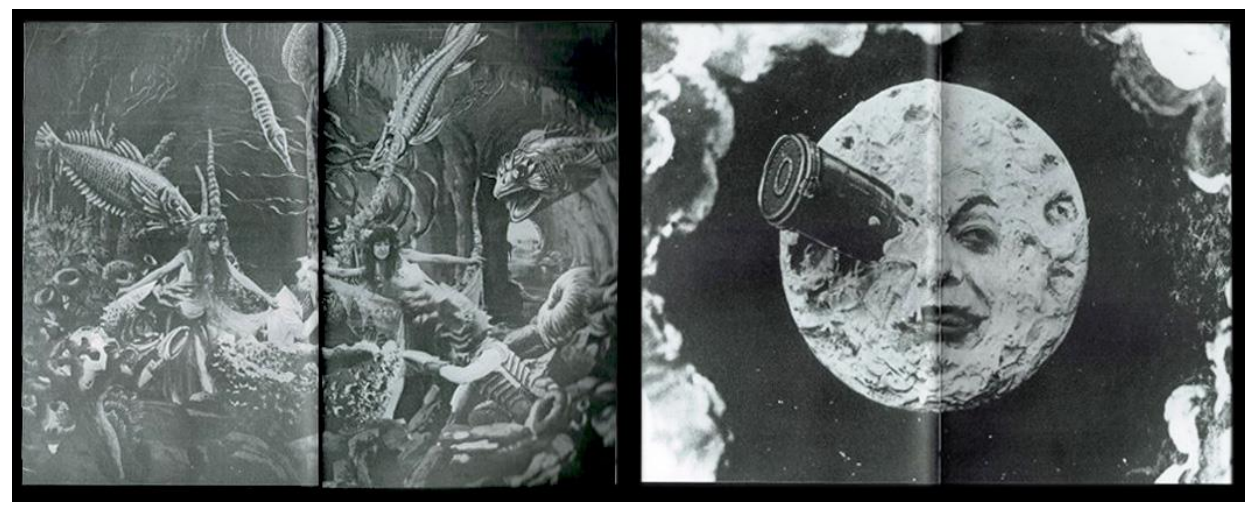

Figura 10: Cenas dos filmes Vinte léguas submarinas e Viagem à lua.

A incorporação da linguagem cinematográfica pode ainda ser observada no jogo que se empreende com os diferentes tipos de enquadramento nas ilustrações, contribuindo para a produção de diferentes efeitos de sentido. Operando com o plano aberto, o plano médio e o grande plano, aliados a traços marcados pela perfeição, Selznick transporta-nos para um mundo quase fotográfico de Paris e dos seus pequenos recantos, possibilitando o jogo entre os planos de pormenor e os grandes planos, a (re)criação e potencialização dos sentidos suscitados pela narrativa. Outra técnica empregada pelo autor e ilustrador consiste na limitação de recursos nas ilustrações e no uso da luz e sombra como parte da narrativa, isto é, o uso da luz como "cor", assemelhando o seu desenho aos primórdios do cinema. Desta forma, a sua ilustração segue um ritmo realista, no qual as formas não se definem pelo contorno, mas sim pelo contraste, de modo que é a luz que dá vida ao desenho, assim como na fotografia e no cinema.

O uso da perspetiva é outro artifício da sintaxe compositiva do cinema incorporado por Brian Selznick. Considerando que a maior parte das ações da narrativa acontece dentro das paredes da estação ferroviária, onde Hugo vive e trabalha secretamente, o uso da perspetiva, aliado ao jogo de ângulos e sombras criados à medida que as páginas são viradas, permite a sugestão de ambientes interiores claustrofóbicos e o aumento da profundidade dos longos corredores escuros e passagens 
ocultas que se evidenciam nas ilustrações, aspeto esse que contribui decisivamente para a construção da atmosfera de mistério que percorre toda a narrativa.

A Chegada, do autor e ilustrador australiano Shaun Tan, publicada em território brasileiro em 2015, também pela editora SM, é outro exemplo de livro-álbum sem palavras que estabelece profícua interseção com o cinema. Nele, ainda que não haja a menção temática à sétima arte conhecemos as adversidades experimentadas por um imigrante, antecedidas pela tensão que determina o abandono da terra de origem em busca de uma vida melhor em terras estrangeiras - , a incorporação da sintaxe cinematográfica na sua composição é notável, uma vez que o livro conta com mais de 700 quadros, de tamanhos variados e vinhetas articuladas entre si.

Se, às vezes, um quadro ocupa toda a página ou páginas duplas; outras vezes, uma página apenas possui sessenta quadros, cada um deles sendo parte do discurso e trazendo uma situação, ação ou emoção que contribui para tecer as mudanças de vida da personagem.
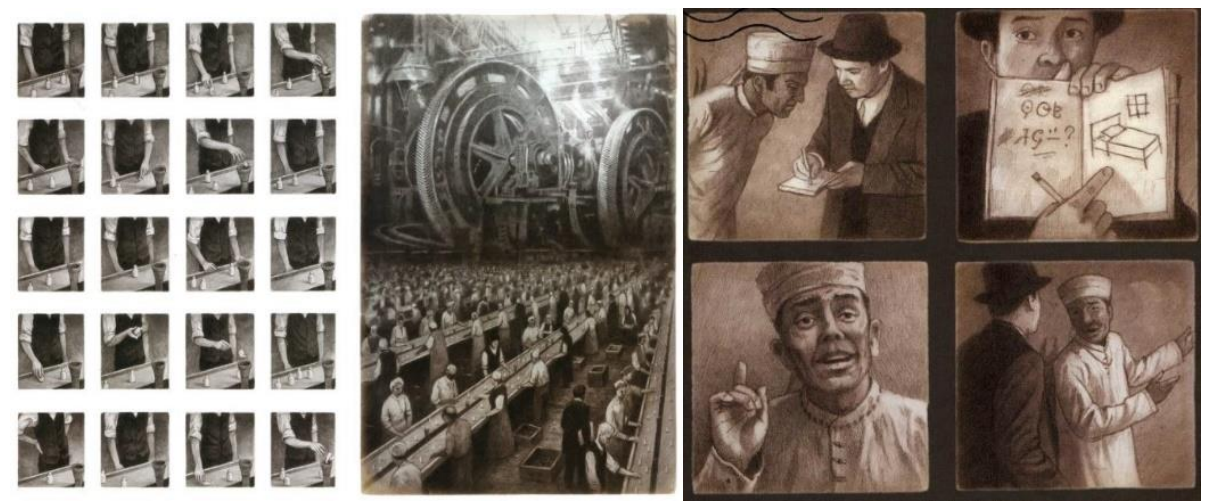

Figura 11: Jogo de quadros na página de $A$ Chegada e emprego de diferentes planos.

O jogo com os diferentes planos é, conforme observado na figura 11, também trazido pela ilustração: se os panoramas constroem cenários amplos, que nos distanciam dos sentimentos que envolvem as personagens; e os grandes planos, ao contrário, aproximam-nos delas, redimensionando os significados construídos; a sequência de quadros com imagens apresentando poucas alterações entre si, por sua vez, contribui para criar a sensação de um breve gesto, do qual se observa cada movimento. Soma-se o emprego de diferentes ângulos, como se o ilustrador estivesse dotado de uma câmara: ora colocado à altura dos olhos das personagens, ora colocado em cima, ora posto para as ver de baixo para cima, deslocamentos esses que convidam o leitor a tornarse um coautor, capaz de interpretar uma pluralidade de emoções e sensações, sugeridas em função das técnicas compositivas empregadas. A escolha de uma paleta monocromática, em tom sépia, colabora também para o efeito de indistinção temporal e longinquidade que se verifica nos quadros, nos quais há a inclusão de cenas e cenários realistas paradoxalmente permeados, em vários momentos, por figuras de animais ou seres estranhos, surreais, que promovem a interação entre o 
real e a imaginação à semelhança do que também encontramos no cinema.

Como se pode observar nos exemplos apresentados, muito além de recuperar o cinema enquanto tema ou motivo ao qual se alude, os livros-álbum contemporâneos incorporam técnicas cinematográficas na sua composição, promovendo a expansão dos sentidos gerados pelo texto e/ou ilustração.

\section{Recriação do filme $A$ janela indiscreta no formato livro-álbum: o caso de $1 .^{\circ}$ Direito}

Publicado em fevereiro de 2020, com chancela da editora Pato Lógico, o livro-álbum 1. ${ }^{\circ}$ Direito, com texto de Ricardo Henriques e ilustrações de Nicolau, é, como os próprios criadores assumem, inspirado no filme de Alfred Hitchcock Rear Window (1954) [Janela Indiscreta], protagonizado por James Stewart e Grace Kelly, funcionando, ainda, como homenagem a Hal Pereira, diretor ${ }^{8}$ de arte cinematográfica que colaborou assiduamente com o cineasta americano. Será Hal Pereira a misteriosa personagem que vem ocupar o $1 .^{\circ}$ Direito do prédio em frente à janela de Graça, a protagonista da narrativa, despertando a sua curiosidade e os seus instintos detetivescos. À semelhança da narrativa cinematográfica hitchcockiana, a protagonista está também presa em casa, por razões que só mais à frente descobrimos. Para ocupar o tempo, diverte-se a observar os vizinhos do prédio da frente à janela, identificando todas as suas atividades e rotinas. Contudo, o vizinho do 1. ${ }^{\circ}$ Direito permanece um mistério e Graça teme que ele seja um criminoso, acabando por descobrir que se trata de um escritor reservado, a tentar terminar o seu livro, com cujo lançamento termina a narrativa, numa sugestiva mise en abyme, já que o livro se intitula $1 .^{\circ}$ Direito. História de uma janela indiscreta, apresentando inúmeras semelhanças visuais e gráficas com a obra aqui em análise. O livro é ainda devedor de outras influências marcantes, como é o caso do romance policial e o de espionagem, não faltando alusões paródicas ${ }^{9}$ a alguns dos seus principais cultores na contracapa, onde surgem críticas apócrifas à publicação assinadas por Ião Flamingo e Ágata Cristina (fig. 12).

\footnotetext{
${ }^{8}$ De origem portuguesa, o seu avô paterno era de ascendência judaica sefardita portuguesa.

${ }^{9} \mathrm{O}$ comentário auto-irónico também surge pela voz da própria narradora quando, depois de desvendado o mistério da identidade do vizinho, refere: “Andei a fazer filmes na minha cabeça” (Henriques, 2020, s/p).
} 


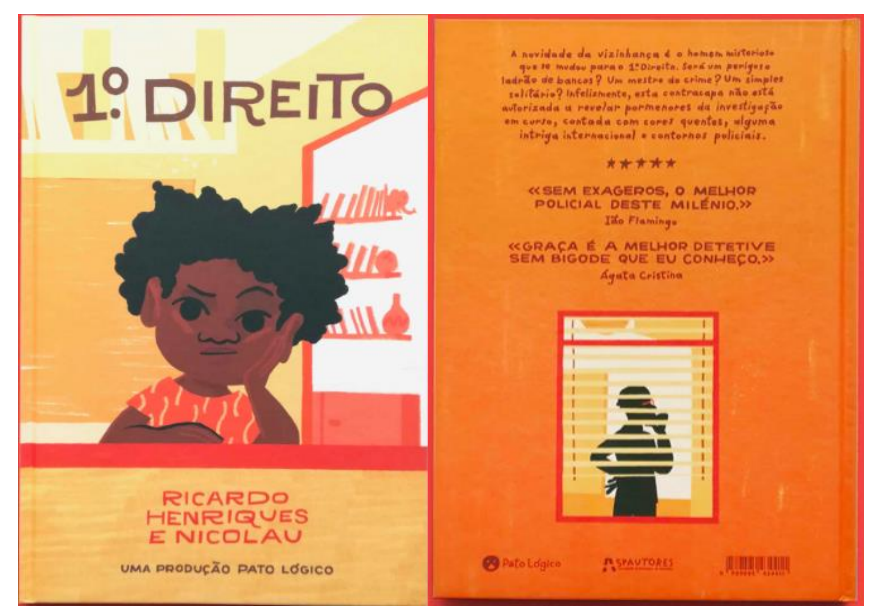

Figura 12: Capa e contracapa do livro-álbum.

A convocação do imaginário fílmico tem relevo logo nos principais elementos peritextuais, como é o caso da capa, sendo o livro-álbum apresentado como "Uma Produção Pato Lógico" (fig. 12), numa apropriação do discurso e do conceito usado no cinema, mas também do uso da classificação de cinco estrelas na contracapa, estratégia habitual na crítica cinematográfica. A folha de rosto (fig. 13) segue o mesmo tempo de procedimentos, substituindo a autoria do livro pela designação de "realização", mantendo a sugestão de que estamos perante uma produção cinematográfica, além de aludir subtilmente ao filme que serve de inspiração ao livro, definindo a publicação como "uma história com intriga, muitas janelas e uma graça ${ }^{10}$ indiscreta". Para além das semelhanças existentes entre filme e livro em termos de proposta narrativa, com óbvias simplificações, do segundo, de onde está ausente a efetivação do crime e até mesmo a centralidade do tema do voyeurismo, são vários os procedimentos técnicos que resultam da apropriação do discurso ou da escrita fílmica na construção da narrativa verbo-icónica.

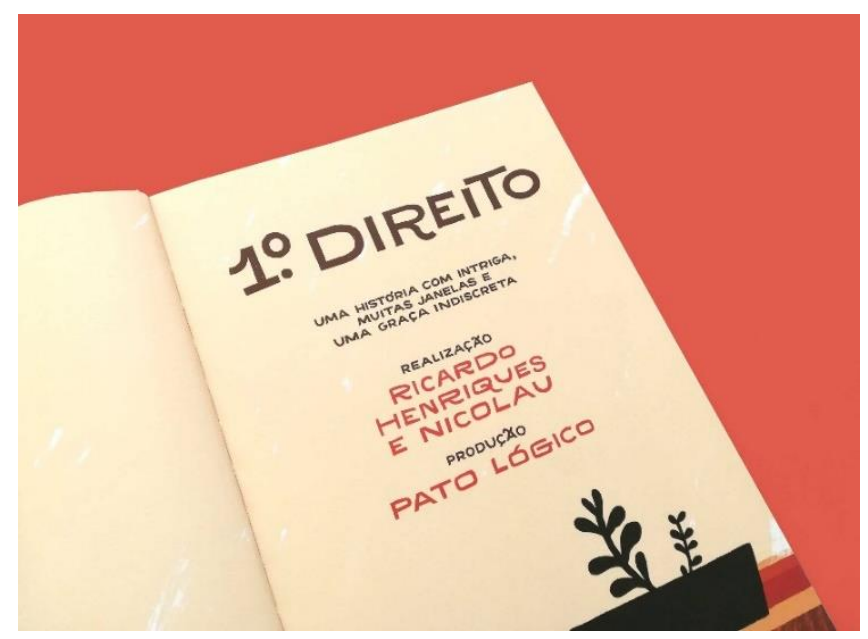

Figura 13: Folha de rosto.

\footnotetext{
${ }^{10} \mathrm{O}$ uso das maiúsculas não permitirá, no início, a identificação da referência à personagem principal, dado que Graça pode ser nome próprio ou comum.
} 
Assim, destaque-se, desde logo, a contenção cromática que domina todo o volume, dominado por uma paleta de tons quentes, com variações que asseguram a representação da passagem do tempo e de momentos diferentes do dia. Os efeitos de transição do dia para a noite, por exemplo, são expressos exclusivamente com recurso à variação cromática, com o escurecimento de uma sucessão de três duplas páginas (fig. 14) que, logo no início da história, contextualizam não só o espaço central da ação, mas também o objeto de interesse da protagonista. Os apartamentos do prédio em frente, "como se fossem canais de televisão", surgem iluminados de modo a dar destaque às personagens que os habitam de modo diferenciado, tirando também partido das sugestões de movimento das personagens entre as várias imagens.

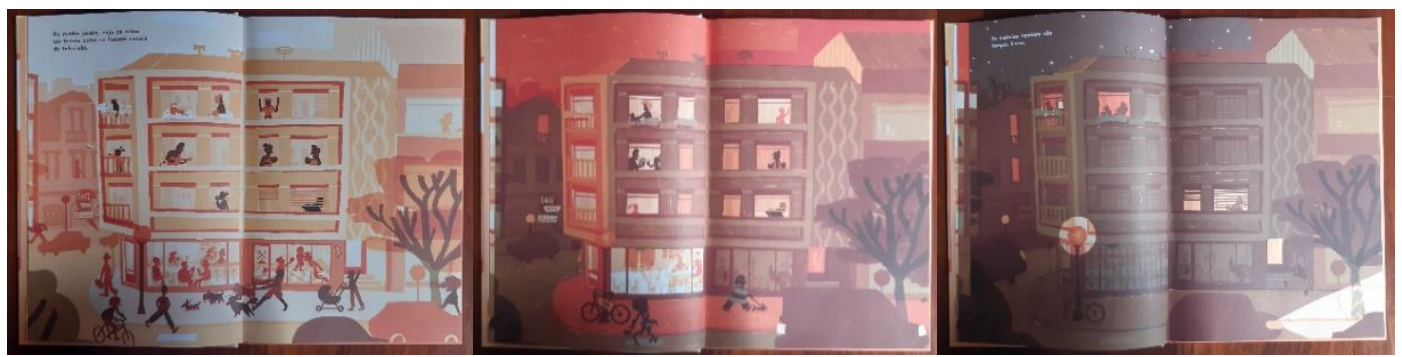

Figura 14: Sucessão de três duplas páginas (efeitos da iluminação e da passagem do tempo).

A questão da iluminação, particularmente cara ao processo de produção cinematográfica, é explorada aqui com grande relevância, pondo em destaque determinadas cenas ou elementos narrativos mais importantes e é interessante verificar até como a iluminação natural dá lugar à artificial à medida que a noite se instala, com a alteração dos diferentes focos de luz. As guardas iniciais e finais, apresentando variação entre si, também podem ser interpretadas como remetendo para a abertura e para o fecho do livro, quer pela variação de cor, entre o dia e a noite, quer pela sugestão da abertura e fecho das persianas, numa alusão ao fade in e fade out cinematográficos.

A questão da arquitetura do livro, que oscila entre o recurso predominante à dupla página como unidade de leitura, e a inclusão de sequências de página simples (para apresentar, num movimento ascendente, os vários apartamentos e os seus habitantes), sem esquecer a segmentação da página em "vinhetas" mais pequenas no clímax da ação, tirando partido do momento dramático e do ritmo mais veloz da intriga, tem impacto no processo e no ritmo de leitura, introduzindo variações que quebram a monotonia. São elementos que decorrem quer do processo de montagem, quer ainda, a montante, das tomadas de imagem, nomeadamente dos enquadramentos e dos ângulos (horizontal e vertical). Assim, veja-se como, logo na abertura, temos um grande plano frontal da protagonista, para, na dupla seguinte, sem que ela se mova da posição inicial, o plano já seja posterior, permitindo ao leitor ter acesso àquilo que ela observa (fig. 15). Este tipo de ângulo, usado, por exemplo, por Gus Van Sant com assiduidade no filme Elephant (2003), permite uma identificação 
do leitor com a personagem, neste caso também narradora, sendo a partir do seu ponto de vista (e focalização interna) que as restantes imagens são recriadas. A fusão do olhar do leitor com o olhar da personagem facilita a adesão à sua visão do mundo.

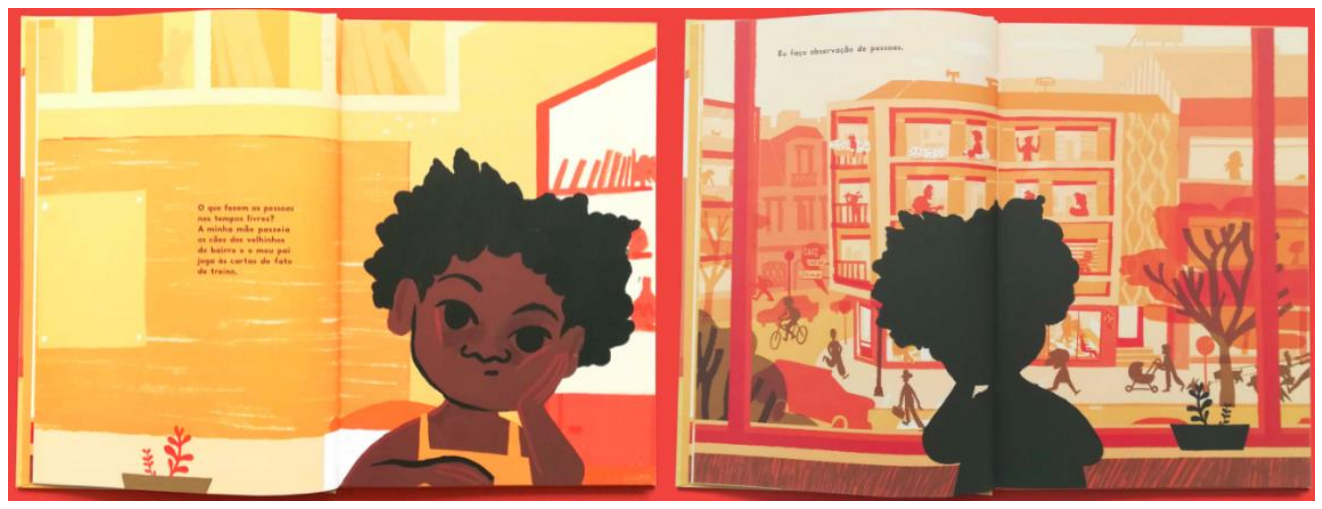

Figura 15: Exemplo de movimento de plano frontal para plano posterior.

Em outros momentos, explora-se a alternância entre aquilo que a personagem vê e a sua reação, como acontece no clímax da intriga, tirando partido do suspense e da incerteza sobre o desenrolar dos acontecimentos. Neste caso, a diminuição do tamanho das imagens, que surgem emolduradas a vermelho, no centro da página, reforça esta sugestão.

De notar também que a personagem principal é quase sempre apresentada à janela, num enquadramento que oscila entre o grande plano e o plano americano, com exceção das três últimas duplas páginas, em que Graça sai finalmente de casa para ir ao lançamento do livro, nas quais é possível ver a razão da sua estadia em casa, já que se move com o auxílio de muletas e apresenta uma perna engessada ${ }^{11}$. Também nesta cena final assistimos a uma alteração da perspetiva, já que o ponto de vista deixa de ser a janela de Graça, para passar a ser o interior do café onde decorre o lançamento do livro de Hal Pereira.

Em termos de estruturação da narrativa, predominantemente sequencial, seguindo uma linha cronológica clara, há lugar para a pausa descritiva, logo no início, quando da apresentação dos ocupantes do prédio da frente, dominada pela simultaneidade. A segmentação das páginas, que passam a simples, funciona também como um movimento de zoom, incidindo sobre cada um dos apartamentos de forma isolada, dando-lhes mais detalhe e definição. O movimento ascendente, que começa com uma dupla página onde são apresentados os espaços comerciais do rés do chão, o café e a barbearia, sobe para os andares superiores, casa a casa, num total de 6 páginas simples, com a exceção para o apartamento $1 .^{\circ}$ Direito, onde reside o mistério que justifica o destaque da narradora: "No 1. ${ }^{\circ}$ direito mora um mistério. Deixei para o fim porque acabou de se mudar. Há uma semana que observo naquela janela um homem de ar sério, que passa os dias a olhar para o infinito"

\footnotetext{
${ }^{11}$ Recorde-se que é também esta a limitação física do fotojornalista do filme de Hitchcock.
} 
(Henriques, 2020, s/p). O facto de ser a única das seis casas que apresenta as persianas fechadas, desde o início do livro, adensa o mistério. Aliás, a abertura das persianas no clímax da história acaba por ser um elemento revelador do "segredo" e manter-se-á até ao final.

Outro aspeto a ter em conta é o do som, presente não só nas falas das personagens, mas também na banda-sonora ou nos efeitos sonoros de vários tipos, com relevo assinalável no próprio desenrolar da ação.

As referências auditivas surgem de forma explícita, como a música do concerto de Roberto Raposo, os seus ensaios no apartamento, mas também a música que os pais de Graça ouvem em casa, sem esquecer as conversas que Graça ouve em casa dos vizinhos ou no café, além do choro das crianças ou o toque da campainha, por exemplo, mas também implícita, associada aos sons da rua, nomeadamente do trânsito. É através de informações textuais e visuais que o leitor deduz a presença de som, como, por exemplo, o toque da guitarra, ou o gira-discos, com a referência à música "Staying Alive”, dos Bee Gees, também ela usada na banda-sonora do filme Saturday Night Fever. Em alguns casos, Graça não tem acesso a toda a informação ou não compreende tudo o que ouve, o que origina perguntas mas também algumas deduções incorretas.

Não se esgotando na análise aqui apresentada, até porque o livro em questão é rico em possibilidades de leitura, por exemplo, em termos de representação alargada da diversidade de

personagens, com relevo para uma protagonista negra, algo raro no contexto português, da desconstrução de estereótipos de vários tipos (género, idade, família...), merece uma nota o caráter crossover da publicação, com múltiplas piscadelas de olho ao leitor adulto, incluindo a referência ao “intertexto" fílmico de Hitchcock, de onde não está ausente uma construção do mundo claramente infantil, marcada por uma certa ingenuidade, visível na interpretação literal de muitas referências e conceitos. Aliás, a dimensão metalinguística do livro, com Graça a questionar-se sobre o significado de palavras e conceitos, reforça esta ideia.

\section{Considerações finais}

O livro-álbum é, por definição, um artefacto multimodal, porque nele confluem texto e ilustração, que, ao criarem uma sinergia especial, um iconotexto único, resultam numa forma de comunicação verbo-icónica singular. A proximidade do livro-álbum com outras formas de comunicação artística também elas multimodais, como a banda-desenhada ou a novela gráfica, parece evidente, dado o recurso a uma gramática semelhante. Mas a distância em relação ao cinema não é, como ficou patente, intransponível, sobretudo quando recordamos que a sétima arte também 
tem claras e estreitas ligações com a fotografia ou com a narrativa textual. O livro-álbum, em particular o narrativo, desenvolve-se através de uma sequência de imagens, muitas vezes apresentadas em duplas páginas sucessivas, cuja leitura em contínuo cria ilusão de movimento e de ação. O recurso a técnicas cinematográficas e fotográficas específicas, ao nível da perspetiva e do ponto de vista, do enquadramento, do uso de planos diferentes, do recurso ao zoom e ao travelling, reforça estas e outras sugestões, trazendo para o espaço plano e imóvel do livro-álbum uma plêiade considerável de possibilidades em termos narrativos.

Os exemplos apresentados ao longo deste estudo demonstram como, muito além de trazer o cinema como temática ou de a ele aludir, as narrativas desenvolvidas nos livros-álbum incorporam técnicas compositivas da linguagem cinematográfica na sua arquitetura, o que contribui de forma decisiva para a expansão dos sentidos gerados pelo texto e/ou ilustração. Convidados a acionarem os seus repertórios literário e cinematográfico, aos leitores são apresentadas as ténues fronteiras entre os discursos artísticos na contemporaneidade e a potencialidade que emerge do diálogo interartes, o que pode ser claramente observado na análise aqui proposta do livro-álbum $1 .^{\circ}$ Direito. Ainda que a obra possa ser lida independentemente da relação que aqui estabelecemos com o filme Janela Indiscreta, de Alfred Hitchcock, fica evidente que a leitura vê os seus sentidos ampliados à medida que o diálogo interartes é proposto. Isto porque, além dos sentidos já gerados pela tríade multimodal texto-ilustração-projeto gráfico que constitui o livro-álbum, se estabelece ainda um diálogo intertextual e arquitetónico adicional com o referido filme, promovendo a (re)construção de outros possíveis significados, o que demanda, certamente, um leitor ativo e capaz de apreender e concatenar as diferentes linguagens que, simultaneamente, compõem o livro.

Desta maneira, ainda que dispondo de meios compositivos distintos e, portanto, mantendo suas especificidades, literatura e cinema mantêm um profícuo e rico diálogo no livro-álbum, demonstrando a multimodalidade e a sofisticação que se evidenciam neste formato preferencialmente endereçado a crianças e jovens leitores na contemporaneidade, bem como a pluralidade de abordagens críticas possíveis de serem empreendidas no seu estudo.

\section{Referencias bibliográficas}

\section{Obras infantis analisadas/mencionadas}

ANTUNES, A. (2016). Imagem. Carcavelos: Planeta Tangerina (il. Yara Kono).

BROWNE, A. (2008). A minha mãe. Lisboa: Caminho. 
BROWNE, A. (1983). Gorilla. London: Julia MacRae Books.

BROWNE, A. (1997). Willy the Dreamer. London: Walker.

BROWNE, A. (2005). King Kong. From the story conceived by Edgar Wallace \& Merian C. Cooper. London: Picture Corgi.

COELHO, M. (2012). Cine Bijou. São Paulo: Cosac Naify/SESC SP (il. Caco Galhardo).

COUSINS, L. (2014). Maisy goes to the movies. Somervile: Candlewick Press.

HENRIQUES, R. (2020). 1. ${ }^{\circ}$ Direito. Lisboa: Pato Lógico (il. Nicolau).

HOOGSTAD, . (2019). Monstros. São Paulo: Amelí.

MARTINS, I. M. (2008). O mundo num segundo. Oeiras: Planeta Tangerina (il. Bernardo Carvalho).

MARTINS, I. M. (2014). Daqui ninguém passa. Carcavelos: Planeta Tangerina (il. Bernardo Carvalho).

MASSI, A. (2016). Monstros do cinema. São Paulo: Sesi (il. Daniel Kondo).

MORAES, O. (2010). O Presente. São Paulo: Cosac Naify.

MURROW, V. (2016). The Whale. London: Templar (il. Ethan Murrow).

ONDJAKI (2013). Uma escuridão bonita. Estórias sem luz elétrica. Lisboa: Caminho (il. António Jorge Gonçalves).

PESSOA, A. (2020). Desvio. Carcavelos: Planeta Tangerina (il. Bernardo Carvalho).

SELZNICK, B. (2011). A invenção de Hugo Cabret. São Paulo: SM.

SOBRAL, C. (2014). O meu avô. Lisboa: Orfeu Mini.

TAN, S. (2011). A Chegada. São Paulo: SM.

VEGARA, I. S. (2018). Audrey: My first Audrey Hepburn. London: Frances Lincoln (il. de Amaia Arrazola).

\section{Estudos e obras teóricas}

BECKETT, S. L. (2012) Crossover Picturebooks: A Genre for All Ages. New York/London: Routledge.

BOLTER, D. J. e GRUSIN, R. A. (2000). Remediation: Understanding New Media. Cambridge: MIT Press. 
GRODAL, T. (2005). "Film narrative”. En HERMAN, D., MANFRED, J. e RYAN, M-L. (eds.), The Routledge Encyclopedia of Narrative Theory (pp. 168-172). New York/London: Routledge.

KUHN, M.; SCHMIDT, J. N. (2014). "Narration in Film”. En HÜHN, P., MEISTER, J. C., PIER, J. e SCHMID DE GRUYTER, W. (eds.), The living handbook of narratology (s/p). Hamburg University. https://doi.org/10.1515/9783110316469

KÜMMERLING-MEIBAUER, B. (2015). "From baby books to picturebooks for adults: European picturebooks in the new millennium”. Word \& Image, 31 (3), 249-264. https://doi.org/10.1080/02666286.2015.1032519

KURWINKEL, T. (2018). "Picturebooks and Movies". En KÜMMERLING-MEIBAUER, B. (ed.), The Routledge companion to picturebooks (pp. 325-336). New York/London: Routledge.

MACKEY, M. (2002). Literacies across Media:Playing the Text. New York/London: Routledge.

NIKOLAJEVA, M. (2002). “The Verbal and Visual: The Picturebook as a Medium”. En SELL, R. D. (ed.), Children's Literature as Communication: The ChiLPA Project (pp. 85-108). Amsterdam: John Benjamins.

NODELMAN, P. (1986) Words about Pictures: The Narrative Art of Children's Picture Books. Athens: University of Georgia Press.

RYAN, M.-L. (2012). "Narration in Various Media”. En HÜHN, P., MEISTER, J. C., PIER, J. e SCHMID DE GRUYTER, W. (eds.), The living handbook of narratology (s/p). Hamburg University. https://doi.org/10.1515/9783110316469

ROSEN, M. (2005). "Radio, Television, Film, Audio and Video”. En HUNT, P. (ed.), International Companion Encyclopedia of Children's Literature (pp. 523-531). New York/London: Routledge.

SHULEVITZ, U. (1996). “What Is a Picture Book?”. En EGOFF, S., STUBBS, G. T., ASHLEY, L. F. e SUTTON, W. (eds.), Only Connect (pp. 238-241). Oxford: Oxford UP.

SPAULDING, A. E. (1995). The Page as a Stage Set: Storyboard Picture Books. Lanham: Scarecrow Press.

THIELE, J. (2000). Das Bilderbuch: Ästhetik, Theorie, Analyse, Didaktik, Rezeption. Isensee.

WOLF, Werner (2005). "Intermediality". En HERMAN, D., JAHN, M. e RYAN, M-L. (eds.). The Routledge Encyclopedia of Narrative Theory (pp. 252-256). New York/London: Routledge. https: //doi.org/10.4324/9780203932896

WOLF, Werner (2008). “The Relevance of 'Mediality' and 'Intermediality' to Academic Studies of English Literature”. En Heusser, M., FISCHER, A. e JUCKER, A. H. et al. (eds.). Mediality / Intermediality (pp. 15-43). Göttingen: Narr. 